\title{
Nuclear magnetic resonance analysis of freeze-thaw damage in natural pumice concrete
}

\author{
Xiaoxiao Wang ${ }^{\mathrm{a}, \mathrm{b}}$, Xiangdong Shen ${ }^{\mathrm{b}} \bowtie$, Hailong Wang ${ }^{\mathrm{b}}$, Chu Gao ${ }^{\mathrm{b}}$, Tong Zhang ${ }^{\mathrm{b}}$ \\ a. College of Civil Engineering, Inner Mongolia University of Technology, (Hohhot, China) \\ b. College of Water Conservancy and Civil Engineering, Inner Mongolia Agricultural University, (Hohhot, China) \\ \ndsxd@163.com
}

\begin{abstract}
This paper presents an analysis of the damage propagation features of the pore structure of natural pumice lightweight aggregate concrete (LWC) under freeze-thaw cyclic action. After freeze-thaw cycling, we conducted nuclear magnetic resonance (NMR) tests on the concrete and acquired the porosity, distribution of transverse relaxation time $T_{2}$, and magnetic resonance imaging (MRI) results. The results showed the following. The $T_{2}$ distribution of the LWC prior to freeze-thaw cycling presented four peaks representative of a preponderance of small pores. After 50,100, 150, and 200 freeze-thaw cycles, the total area of the $T_{2}$ spectrum and the porosity increased significantly. The MRI presented the changing spatial distribution of pores within the LWC during freeze-thaw cycling. Ultrasonic testing technology was applied simultaneously to analyze the NMR results, which verified that the new NMR technology demonstrated high accuracy and practicability for research regarding freeze-thaw concrete damage.
\end{abstract}

KEYWORDS: Natural pumice concrete; Damage extension; Nuclear magnetic resonance (NMR); Porosity; Relaxation time

Citation/Citar como: Xiaoxiao Wang.; Xiangdong Shen.; Hailong Wang.; Chu Gao.; Tong Zhang. (2016) Nuclear magnetic resonance analysis of freeze-thaw damage in natural pumice concrete. Mater. Construcc. 66 [322], e087. http://dx.doi.org/10.3989/mc.2016.09014.

RESUMEN: Análisis por resonancia magnética nuclear del deterioro en hormigón con piedra pómez tras ciclos hielo-deshielo.En este trabajo se analiza la propagación de los daños que se producen en la estructura porosa de hormigón aligerado a base de piedra pómez natural sometido a la acción cíclica de hielo-deshielo. Después de realizarse los ensayos de hielo-deshielo, el hormigón se analizó mediante resonancia magnética nuclear (RMN), determinándose la porosidad y la distribución del tiempo de relajación transversal, $T_{2}$, y registrándose las imágenes captadas por resonancia magnética. De acuerdo con los resultados obtenidos, antes de los ciclos de hielodeshielo la distribución de $T_{2}$ del hormigón aligerado presentaba cuatro picos, indicativos de un predominio de poros pequeños. Después de que se sometiera a 50, 100, 150, y 200 ciclos, se observó un aumento importante tanto de la porosidad como de la superficie total del espectro de $T_{2}$. Las imágenes captadas por resonancia magnética evidenciaron la modificación de la distribución espacial de los poros del hormigón aligerado durante el ensayo. Por otra parte, mediante la comprobación por técnicas de prospección ultrasónica se confirmó que la nueva tecnología $\mathrm{RMN}$ es de alta precisión y gran practicidad en la investigación de los daños producidos en el hormigón por los ciclos de hielo-deshielo.

PALABRAS CLAVE: Hormigón de piedra pómez natural; Propagación de daños; Resonancia magnética nuclear (RMN); Porosidad; Tiempo de relajación

Copyright: (C) 2016 CSIC. This is an open-access article distributed under the terms of the Creative Commons Attribution-Non Commercial (by-nc) Spain 3.0 License. 


\section{INTRODUCTION}

Throughout the remainder of the 21st century, and even longer in China, concrete materials are expected to continue to be among the most important building materials, and concrete structures will continue to be the dominant structures employed in civil engineering $(1,2)$. Conventional concrete, being itself heavy, results in very heavy concrete structures, which leads to significant disadvantages, and limits the development of potential civil engineering projects. A lightweight high-strength concrete material is therefore greatly required (3-6). Lightweight natural pumice aggregate concrete has emerged in response to these engineering needs $(6,7)$. For conventional concrete, crushed stones are applied as coarse aggregate. The crushed stones are comprised of natural rocks, cobbles, or waste stones, which have been generally obtained from mining areas through sieving of materials derived from mechanical disruption processes such as drilling, blasting, and crushing, with grain sizes greater than $5 \mathrm{~mm}$. Unfortunately, these processes produce a prodigious amount of dust that pollutes the environment and causes damage to the health of surrounding residents and workers $(5,6)$. Moreover, noise pollution is also produced, which further harms the environment. This is yet another reason to promote the development of natural pumice concrete.

Natural lightweight aggregate is comprised of porous, lightweight rocks such as scoria and pumice stone, which are types of porous vitreous extrusive rock formed by volcanic eruptions. France, Japan, Italy, and the former Soviet Union are all countries that possess abundant volcanic rock resources. Lightweight aggregate played an active role in the restoration and construction of cities after World War II (7). Available volcanic resources are extremely rich in China as well, and are widely distributed. This is particularly the case in the Inner Mongolia area, where the demonstrated reserve of 11 confirmed volcanic clusters including abundant raw materials of natural lightweight aggregate (8) is approximately 2 billion $\mathrm{m}^{3}$, which excludes the resource statistics of 17 other volcanic clusters and the massive volcanic clusters in Jilin Province. Pumice stone and scoria are non-metallic minerals that are widely distributed in large quantities throughout China, mainly in the northeast, north, and south. At present, the mines that have been exploited are the Huinan volcanic slag mine and the Antu Yuanchi pumice mine in Jilin Province, the Kedong Erkeshan pumice mine in Heilongjiang Province, the Lanhada pumice mine in Inner Mongolia, and the Hainan pumice mine. Five million $\mathrm{m}^{3}$ of minerals have thus far been exploited from only the five provinces of Heilongiiang, Jilin, Shanxi, Liaoning, and Inner Mongolia, and it is possible for these sources to support present utilization for the next 100 years, whereas China possesses substantial potential for further exploration (9).
In this paper, the natural pumice stone derived from the Inner Mongolia area is the research object. Lightweight aggregate concrete (LWC) has been widely used in recent years due to its high porosity, low density, frost resistance, and favorable heat retaining property $(8,10-14)$. In the northern area of China, the damage to hydraulic concrete, such as dams (see Figure 1), is relatively large owing to cyclic freezing and thawing. Due to seasonal changes and the diurnal cycle, the concrete materials of hydraulic structures sustain the physical weathering caused by freeze-thaw cycling, which results in extension and propagation in the internal micro-fractures of the concrete. The internal texture degrades and affects the physical and mechanical properties of the concrete materials. As a result, these large-scale concrete structures generally remain functional for only about 30 years, and some for even less than 10 years. Moreover, concrete structures that are subject to contact with saline water suffer particularly greatly from frost damage $(15,16)$. Therefore, it is of significance to analyze and understand the variational features of the microstructure of concrete under freeze-thaw conditions for the purpose of establishing the mechanisms of concrete freeze-thaw damage and the corresponding failure mechanisms of concrete structures in cold regions.

Many rewarding studies have been conducted by scholars from around the world concerning LWC. Alengaram and Khokhrin $(4,17)$ found that, at a strength level of $30-40 \mathrm{MPa}$, the water permeability of LWC was lower than that of corresponding conventional concrete. Numerous other studies $(9,10,12,18,19)$ have shown that the use of fibers in LWC is an appropriate solution to resolve problems associated with the material's higher brittleness and reduced mechanical properties. For example, researchers $(5,6)$ have investigated the use of oil palm shell as an additive fiber for LWC, and the

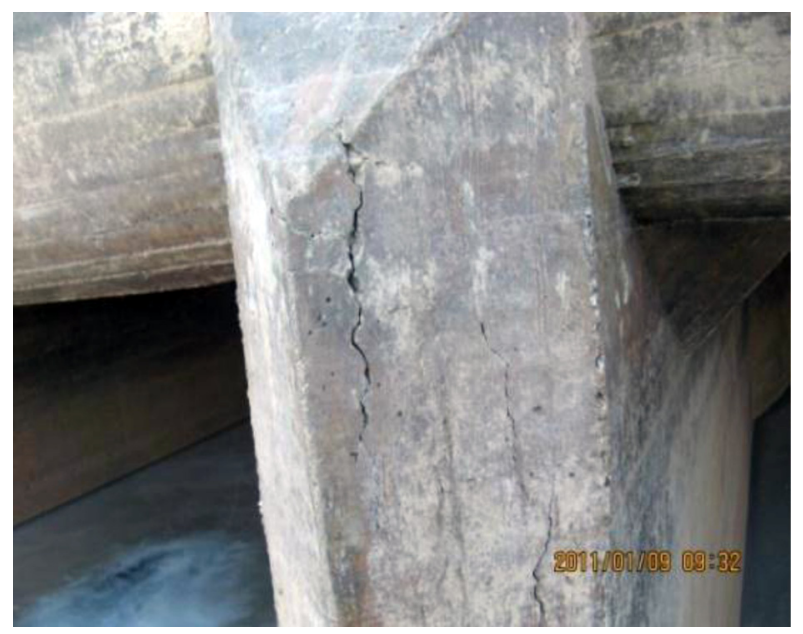

FIGURE 1. An example of freeze-thaw damage of a dam sluice. 
production of medium and high strength LWC was demonstrated. The strength, stiffness, and durability of fly ash lightweight concrete and pumice lightweight concrete have been studied (20-22). In another study (23), five types of manufactured lightweight aggregate were used to establish prediction models based on the stress-strain relationship, compressive strength, elastic modulus, and peak strain of the resulting LWC, and another type of lightweight aggregate was used to validate them. Lightweight aggregate having a lower pore volume and a greater concentration of small pores was shown to result in LWC that demonstrated good resistance to freezing and thawing (7).

Presently, the microstructure of concrete has been widely studied, and image analysis techniques, such as scanning electron microscopy (SEM) and computed tomography (CT) scanning have been applied for analysis of the microstructure of concrete. Amor Ben Fraj (24) employed SEM to analyze the interfacial zone between the cementitious matrix and lightweight aggregates. Other researchers (25-29) employed CT to examine the pore structure and permeability of asphalt concrete materials, conventional concrete materials, and porous concrete and cement materials. In addition, CT was again used to investigate the spatial void distribution in a LWA (30).

NMR has developed into quite a mature application in fields such as medical diagnosis, petroleum exploration and development, agriculture, and the food and bio-pharmaceutical fields, and has also been widely promoted in research regarding pore structure and the freeze-thaw damage mechanism of rocks (31-33). However, it has been seldom applied in studies of the freeze-thaw damage mechanism of concrete. In the present study, we evaluate concrete obtained using the natural pumice derived from Inner Mongolia as the coarse aggregate material. Cyclic freeze-thaw testing with different numbers of cycles and ultrasonic testing are conducted. We then apply NMR analysis for relaxation and imaging measurements. Finally, we analyze and discuss the distribution of the $T_{2}$ spectrum, variation of the total $T_{2}$ spectrum area, and the internal pore distribution characteristics of natural pumice LWC.

\section{TEST PROFILE}

\subsection{Test materials and instruments}

The following materials were employed. Cement: Jidong P.O42.5 Ordinary Portland Cement with the performance indicators listed in Table 1; coarse aggregate: pumice aggregate of central Inner Mongolia, China (see Figure 2) with the performance indicators listed in Table 2; fine aggregate: natural river sand, fineness modulus 2.56 , silt content $1.98 \%$, bulk density $1,465 \mathrm{~kg} / \mathrm{m}^{3}$, apparent density $2,645 \mathrm{~kg} / \mathrm{m}^{3}$, moisture content $1.987 \%$, favorable grain composition, with the gradations listed in Table 3; fly ash: I-grade fly ash derived from Jinqiao Thermal Power Plant, Hohhot with the chemical composition listed in Table 4; water reducing agent: RSD-8 type superplasticizer, dominant ingredient $\beta$-sodium naphthalene formaldehyde high-condensation, admixture amount 3\%, water-reducing rate $20 \%$, no corrosive action on the rebar; water: ordinary tap water.

The key instruments employed in the testing include a freeze-thaw cycle testing apparatus, ultrasonic testing analyzer, vacuum saturation device, MiniMR-60 type nuclear magnetic resonance

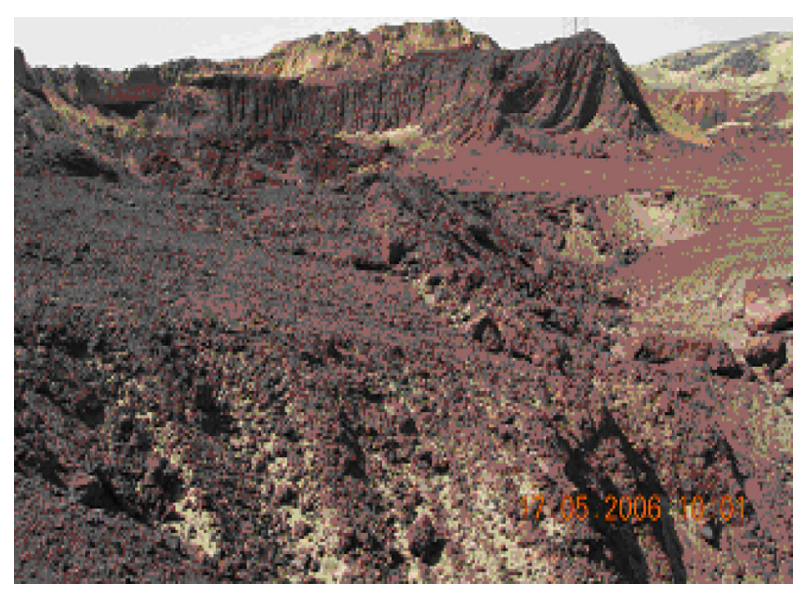

FiguRE 2. The pumice aggregate of central Inner Mongolia, China.

TABLE 1. P.O42.5 Portland cement performance

\begin{tabular}{|c|c|c|c|c|c|c|c|c|c|c|c|}
\hline \multirow[b]{2}{*}{ Test item } & \multirow[b]{2}{*}{ Fineness (\%) } & \multirow{2}{*}{$\begin{array}{c}\text { Initial } \\
\text { setting } \\
\text { time }\end{array}$} & \multirow{2}{*}{$\begin{array}{c}\text { Final } \\
\text { setting } \\
\text { time }\end{array}$} & \multirow[b]{2}{*}{ Soundness } & \multirow[b]{2}{*}{$\mathrm{SO}_{3}(\%)$} & \multirow[b]{2}{*}{ Loss (\%) } & \multirow[b]{2}{*}{$\operatorname{MgO}(\%)$} & \multicolumn{2}{|c|}{$\begin{array}{c}\text { Compressive } \\
\text { strength (MPa) }\end{array}$} & \multicolumn{2}{|c|}{$\begin{array}{c}\text { Flexural } \\
\text { strength (MPa) }\end{array}$} \\
\hline & & & & & & & & $3 \mathrm{~d}$ & $28 \mathrm{~d}$ & $3 \mathrm{~d}$ & $28 \mathrm{~d}$ \\
\hline Measured & 1.2 & $2: 15$ & $2: 55$ & Qualification & 2.23 & 1.02 & 2.21 & 26.6 & 54.8 & 5.2 & 8.3 \\
\hline
\end{tabular}

TABLE 2. The physical properties of the pumice employed as coarse aggregate

\begin{tabular}{lccccc}
\hline Physical property & Bulk density $\left(\mathbf{k g} \cdot \mathbf{m}^{\mathbf{3}}\right)$ & $\begin{array}{c}\text { Apparent density } \\
\left(\mathbf{k g} \cdot \mathbf{m}^{\mathbf{3}}\right)\end{array}$ & $\begin{array}{c}\text { Water absorption } \\
(\mathbf{1} \mathbf{~ h ) ~ ( \% )}\end{array}$ & $\begin{array}{c}\text { Barrel press } \\
\text { strength (MPa) }\end{array}$ & Crushing index (\%) \\
\hline Pumice & 690 & 1593 & 16.44 & 2.978 & 39.6 \\
\hline
\end{tabular}


TABLE 3. The gradation of the natural river sand employed as fine aggregate

\begin{tabular}{ccc}
\hline Sieve aperture (mm) & $\begin{array}{c}\text { The grader retained percentage } \\
(\mathbf{\%})\end{array}$ & $\begin{array}{c}\text { The accumulated retained percentage } \\
(\mathbf{\%})\end{array}$ \\
\hline 4.75 & 1.56 & 1.56 \\
2.36 & 8.32 & 9.88 \\
1.18 & 14.23 & 24.11 \\
0.6 & 29.69 & 53.8 \\
0.3 & 32.08 & 85.88 \\
0.15 & 12.86 & 98.24 \\
$<0.15$ & 1.24 & 100 \\
\hline
\end{tabular}

TABLE 4. Chemical composition of fly ash

\begin{tabular}{lccccccccc}
\hline Component & $\mathrm{SiO}_{2}$ & $\mathrm{Al}_{2} \mathbf{O}_{3}$ & $\mathbf{C a O}$ & $\mathbf{M g O}$ & $\mathbf{S O}_{3}$ & $\mathbf{F e}_{2} \mathbf{O}_{3}$ & $\mathbf{T i O}_{2}$ & $\mathbf{N a}_{2} \mathbf{O}+\mathbf{K}_{2} \mathbf{O}$ & $\begin{array}{c}\text { specific surface area } \\
\left(\mathbf{m}^{2} \cdot \mathbf{k g}^{-1}\right)\end{array}$ \\
\hline $\mathrm{W}(\%)$ & 51.93 & 16.11 & 6.95 & 2.02 & 1.59 & 5.10 & 1.78 & 2.05 & 651 \\
\hline
\end{tabular}

(NMR) spectrometer manufactured by Niumag Electronics \& Technology Co., Ltd.

The principle behind the NMR porosity measurements is as follows. A porous medium is saturated by water, and the initial amplitude of the NMR spin echo string, or the area enclosed by the $T_{2}$ distribution curve, is directly proportional to the number of hydrogen atoms in the porous fluid within the scope of detection. The integral sum of the relaxation spectra represents the fluid content in the test specimen. Therefore, the porosity value of the test specimen can be calculated after performing a suitable calibration of the relaxation spectra. The measurement method is as follows. First, NMR is employed to measure the calibration specimen, the porosity of which has already been obtained by means of a conventional method, and a relationship curve (usually a linear relationship) is established between the porosity and the NMR unit volume signal in accordance with the NMR results of the calibration specimen. NMR is then employed to measure a concrete specimen of unknown porosity, and the unit volume signal amplitude is substituted into the relational expression to calculate the porosity of the specimen.

\subsection{Test method and program}

LC30 strength grade LWC is taken as the research object with a mixture proportion of cement: water:(pumice lightweight aggregate):sand:(fly ash):(water reducing agent) $=360: 180: 530: 690: 730: 90: 9$ by mass A crusher was used to crush the pumice into particles with grain sizes of about $2 \mathrm{~cm}$, and sifters with pore diameters of $22.5 \mathrm{~mm}$ and $9.5 \mathrm{~mm}$ were used to screen out the particles with grain sizes greater than $22.5 \mathrm{~mm}$ and less than $9.5 \mathrm{~mm}$. No prewetting treatment was conducted for the pumice. The mixing procedure employed followed that given in Technical Specification for Lightweight Aggregate
Concrete (JGJ51-2002). The test mold dimensions were $100 \mathrm{~mm} \times 100 \mathrm{~mm} \times 400 \mathrm{~mm}$, and the mold was removed after $24 \mathrm{~h}$, and the test piece was stored under standard conditions.

Freeze-thaw cycle testing was conducted with reference to the operational instructions of the "fast freezing method" freeze-thaw cycle test (GB/T 50082-2009 Standard for Test Methods of Long-term Performance and Durability of Ordinary Concrete), where test pieces stored for $24 \mathrm{~d}$ were steeped in $(20 \pm 2){ }^{\circ} \mathrm{C}$ saline solution obtained from the Hetao Irrigation District for $4 \mathrm{~d}$ until the interior was waterlogged. Freeze-thaw cycling was then conducted with a cycle period of $4 \mathrm{~h}$, where the thawing time was half the freezing time. In the freezing and thawing processes, the minimum and maximum temperatures of the test piece were controlled within $(-18 \pm 2)^{\circ} \mathrm{C}$ and $(5 \pm 2)^{\circ} \mathrm{C}$, respectively. Sets of three concrete blocks each were subjected to testing, and six groups of freeze-thaw cycles were conducted for each set. The numbers of cycles $N$ were $0,50,100,150$, and 200 .

To more comprehensively evaluate the interior pore structures of the LWC samples before and after the freeze-thaw cycling, we removed a test piece every 50 freeze-thaw cycles. As shown in Figure 3, we then cored the test piece with a cutting machine. To eliminate the effects of uneven freeze-thawing at the ends, we removed a $100 \mathrm{~mm} \times 100 \mathrm{~mm} \times 170 \mathrm{~mm}$ section at both ends of the test piece. We further removed a $30 \mathrm{~mm}$ thick perimeter from the outer surface of the remaining section, leaving a residual core sample with dimensions of about $40 \mathrm{~mm} \times 40 \mathrm{~mm} \times 60 \mathrm{~mm}$. This process was designed to eliminate uneven distributions of the effects of uneven freeze-thawing on the formed surface and underside aggregate.

We then conducted NMR analysis on the core samples after different numbers of freezethaw cycles. First, we applied a vacuum saturation device to saturate the concrete sample with 


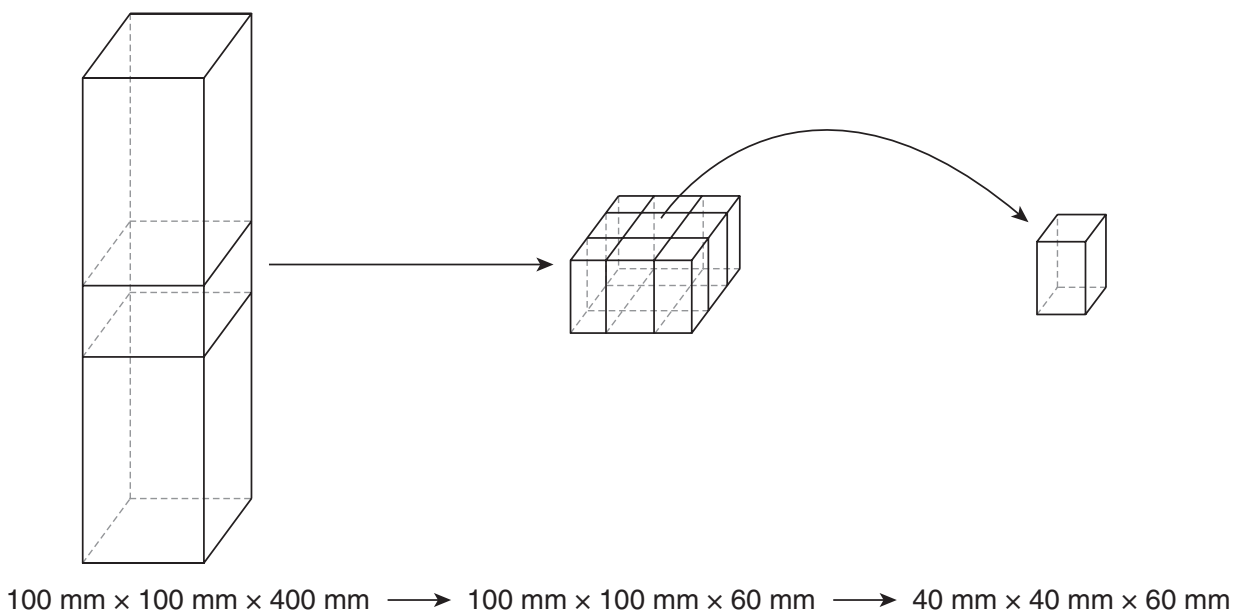

FigurE 3. Obtaining the core sample by cutting the test piece.

water. The vacuum pressure value was $0.1 \mathrm{MPa}$ and the pump-down time was $4 \mathrm{~h}$. We then steeped the sample in distilled water for $24 \mathrm{~h}$ and conducted the process again for NMR relaxation measurements for a comparison analysis. To eliminate the effects of moisture evaporation on the test results, the moisture was wiped from the surface of the samples upon being removed, and each sample was wrapped in a preservative film for NMR analysis.

\section{TEST RESULTS AND ANALYSIS}

\subsection{Ultrasonic testing}

Evaluating the propagation velocity of sound waves in concrete provides related information regarding concrete quality and strength. In general, the propagation velocity of the sound wave increases with increasing strength and integrity of the concrete. Therefore, the physical and dynamic mechanical properties of the concrete are represented by the measured variations of the wave velocity in the concrete before and after freeze-thaw testing, which reflects the damage and defects produced inside the concrete. In this paper, ultrasonic testing was conducted on the concrete before and after freeze-thaw testing, and the obtained results are listed in Table 5.
From Table 5, it can be seen that the wave velocity reduces significantly after the freeze-thawing of the LWC. This indicates that the number of freezethawing cycles causes damage to the interior of the concrete. To quantitatively define the degree of damage, we introduce the reduction rate of the wave velocity $\eta$ and the degree of damage $D(9,34)[1]$ [2]:

$$
\begin{aligned}
& \eta=\left(1-\frac{v}{v^{\prime}}\right) \times 100 \% \\
& D=1-\left(\frac{v}{v^{\prime}}\right)^{2}(0 \leq D \leq 1)
\end{aligned}
$$

Here, $\eta$ is rate at which the sound wave velocity of the concrete diminishes (\%), $v$ is the ultrasonic wave velocity after freeze-thawing $\left(\mathrm{m} \cdot \mathrm{s}^{-1}\right)$, and $v^{\prime}$ is the ultrasonic velocity before freeze-thawing $\left(\mathrm{m} \cdot \mathrm{s}^{-1}\right)$.

Figure. 4 presents the variation curves of $\eta$ and $D$ versus $N$ of the LWC samples. The figure shows that, with increasing $N$, both $\eta$ and $D$ present increasing trends, which are roughly equivalent. The $150^{\text {th }}$ freeze-thaw cycle is observed to represent a critical point, where, when $N$ is less than $150, \eta$ and $D$ change gradually, and, when $N$ is greater than

TABLE 5. Ultrasonic test results of freeze-thaw damage

\begin{tabular}{lcccc}
\hline $\begin{array}{c}\text { Sample } \\
\text { number }\end{array}$ & $\begin{array}{c}\text { Number of freeze-thaw } \\
\text { cycles } N\end{array}$ & $\begin{array}{c}\text { Ultrasonic wave velocity } \\
\text { after freeze-thawing } \boldsymbol{v}\left(\mathbf{m} \cdot \mathbf{s}^{-1}\right)\end{array}$ & $\begin{array}{c}\text { Wave velocity } \\
\text { reduction rate } \boldsymbol{\eta}(\%)\end{array}$ & $\begin{array}{c}\text { Degree of } \\
\text { damage } D\end{array}$ \\
\hline 1 & 0 & 4588 & 0 & 0 \\
2 & 50 & 4387 & 4.4 & 0.09 \\
3 & 100 & 4116 & 10.3 & 0.20 \\
4 & 150 & 3846 & 16.1 & 0.30 \\
5 & 200 & 2500 & 45.5 & 0.70 \\
\hline
\end{tabular}




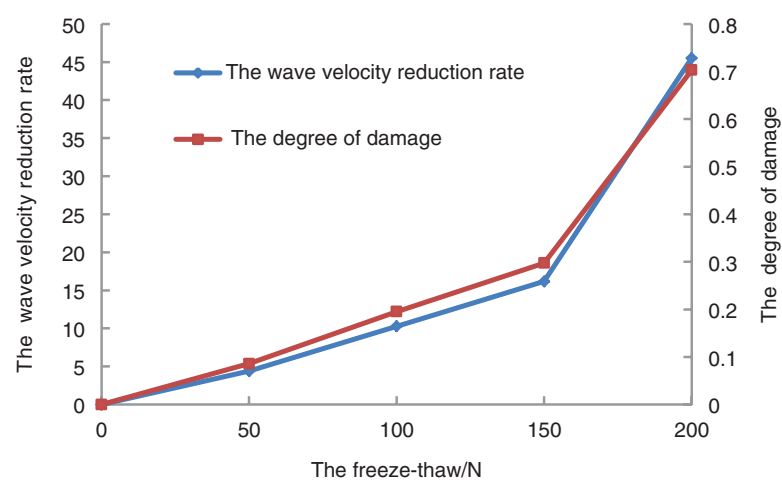

FIgURE 4. The variation curves of the wave velocity reduction rate and degree of damage with respect to the number of freeze-thaw cycles $(N)$ of the lightweight aggregate concrete.

150, $\eta$ and $D$ change rapidly. This indicates that freeze-thaw damage begins to affect the interior of the LWC after 150 freeze-thaw cycles.

\subsection{Porosity of natural pumice concrete}

Porosity is the ratio of the total volume of voids to the total volume of the concrete. Applying NMR analysis, we measured the porosity for different values of $N(0,50,100,150$, and 200). The results are listed in Table 6. The permeability and movable fluid content can be calculated with the porosity and pore distribution provided by the NMR. The cut-off value of $T_{2}$ the boundary value between the bound fluid and free fluid is related to the pore size. If $T_{2}$ is smaller than the cut-off, then the bound fluid correspondingly exists in the small pores, and the $T_{2}$ of the free fluid, which is larger than the cutoff, exists in the large pores. According to the NMR principle, the $T_{2}$ cut-off is usually defined as the $T_{2}$ value at the boundary between the different regions in the distribution. In this study, in order to make a better comparison with the pores of natural pumice LWC in the different freeze-thaw times, based on $T_{2}$ spectrum curves, we obtain the $T_{2}$ cut-off with different times of freeze-thaw cycles, as shown as Table 6.

Figure 5 presents the variation of the natural pumice concrete porosity and fluid saturation with respect

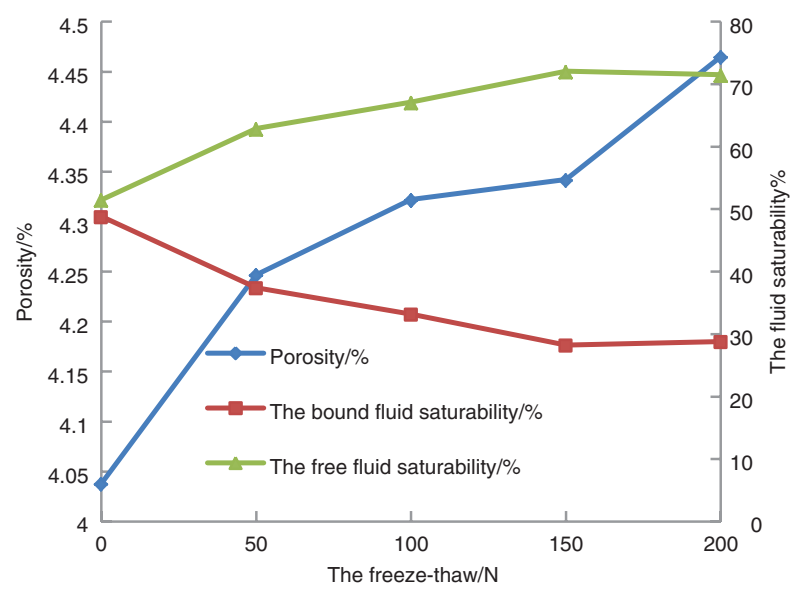

FIGURE 5. Variation curves of natural pumice concrete porosity and fluid saturation with respect to the number of freeze-thaw cycles $(N)$.

to $N$, which indicates that the natural pumice concrete pores enlarge with increasing $N$, and the increasing amplitude of porosity variation differs over each range of freeze-thaw cycling. The extent to which the porosity changes at 50,100,150, and 200 freeze-thaw cycles relative to the porosity at $N=0$, are $5.177 \%, 7.035 \%$, $7.530 \%$, and $10.577 \%$, respectively. For $N$ greater than 100 , successive degrees of porosity increase by a factor of 1-2 relative to the previous value. This indicates that the porosity of the natural pumice concrete is greatly affected by freeze-thaw cycling. With increasing $N$, both $v$ and $D$ increase, the generation and propagation of fractures inside the concrete accelerate, and the porosity changes significantly.

It can also be observed from Figure 5 that the developmental trend of the saturation degree of free fluid is inversely proportional to that of bound fluid, where the saturation degree of bound fluid presents a declining trend with increasing $N$. This indicates that the observed increase in concrete porosity with increasing $N$ is mainly due to an enlarging pore size.

Permeability in the earth sciences is a physical measure of the ability of a medium material to transmit fluids. Figure 6 presents the porosity and permeability of the natural pumice concrete with respect to $N$. The porosity and permeability exhibit similar

TABLE 6. Natural pumice lightweight concrete porosity under different numbers of freezing-thawing cycles

\begin{tabular}{lccccc}
\hline $\begin{array}{l}\text { Number of } \\
\text { cycles } N\end{array}$ & Porosity (\%) & $\begin{array}{c}\text { Bound fluid } \\
\text { saturability (\%) }\end{array}$ & $\begin{array}{c}\text { Free fluid } \\
\text { saturability (\%) }\end{array}$ & $\begin{array}{c}\text { Permeability } \\
(\mathbf{m D})\end{array}$ & $\begin{array}{c}\text { Cut-off } \\
\text { value of } T_{2}\end{array}$ \\
\hline 0 & 4.037 & 48.653 & 51.347 & 225.775 & 3.511 \\
50 & 4.246 & 37.275 & 62.725 & 345.087 & 3.054 \\
100 & 4.321 & 33.049 & 66.961 & 582.042 & 3.054 \\
150 & 4.341 & 28.106 & 71.894 & 743.161 & 2.656 \\
200 & 4.464 & 28.660 & 71.340 & 905.955 & 2.656 \\
\hline
\end{tabular}




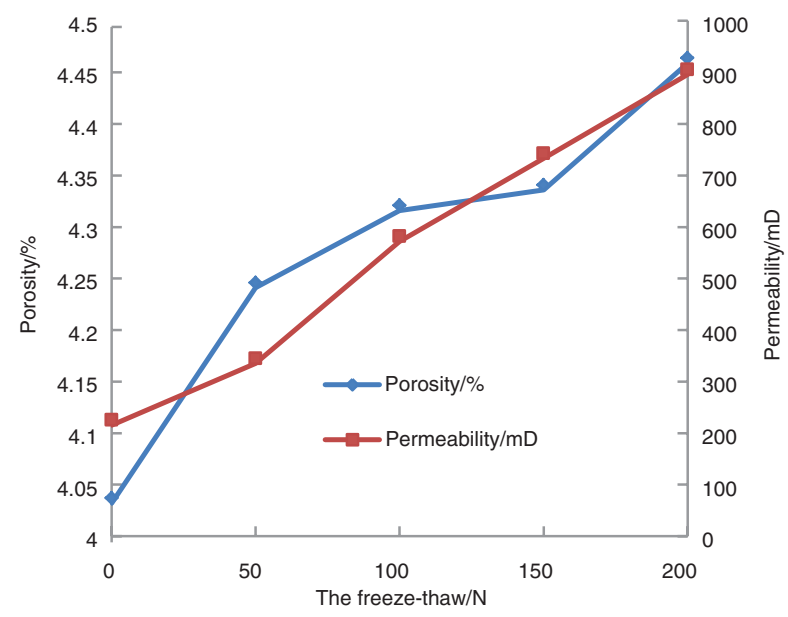

FIGURE 6. Variation curves of natural pumice concrete porosity and permeability with respect to the number of freeze-thaw cycles $(N)$.

behaviors, and the change rule is clear. With increasing porosity, the permeability of concrete presents a linear increase. During 50, 100, 150, and 200 freezethaw cycles, successive permeability values increase by a factor of 1.2-1.7 relative to the previous value.

From the variation of porosity and fluid saturation shown in Figure 5 and the variation of porosity and permeability shown in Figure 6, we know that, with increasing permeability, the bound fluid saturation decreases and the free fluid saturation increases. Because natural pumice is a type of porous medium wherein the connectivity between pores is relatively strong and the percolating resistance is minor, Figure 6 indicates that the permeability of the natural pumice concrete increases with increasing porosity.

The porosity is demarcated by measuring the semaphore of the moisture in the pores of the natural pumice concrete with NMR, and, thus, the reason for the observed increasing porosity with increasing freeze-thaw cycling can be described as follows. The porosity of natural pumice concrete is large itself, and, when conducting freeze-thaw cycling in saline solution, the salts in high concentration within the solution dissociate and are transported to regions of low salt concentration within the concrete owing to the principle of ion equilibration. This results in an increasing degree of the saturation of saline solution within the internal pores of the concrete. The solution freezes and the concrete volume expands. The tension produced in the ice expansion process eventually exceeds the tensile strength of the concrete, and repeated freezing generates fractures inside the concrete. Repeated freezing extends the fractures, further enlarges the pores, and simultaneously increases the water absorption of the concrete. As a result, the freeze-thaw damage is intensified. Therefore, the degree of fracture extension and the number of pores newly produced, and, hence, the degree of damage, differ after different numbers of freeze-thaw cycles; consequently, the amplitudes by which the porosity increases differ between different numbers of freeze-thaw cycles.

\subsection{Distribution of the NMR $T_{2}$ spectrum}

According to the principles of NMR analysis $(35,36)$, the relaxation time $T_{2}$ of a fluid in a porous medium is the result of the joint action of the bulk relaxation time $T_{B}$, surface relaxation time $T_{S}$, and diffusion relaxation time $T_{D}$. This process may be expressed as follows [3]:

$$
\frac{1}{T_{2}}=\frac{1}{T_{B}}+\frac{1}{T_{s}}+\frac{1}{T_{D}}=\frac{1}{T_{B}}+\rho \frac{S}{V}+\frac{D^{\prime}\left(\gamma G T_{E}\right)^{2}}{12},
$$

where $\rho$ is the lateral surface relaxation strength of the porous medium $(\mu \mathrm{m} / \mathrm{ms}), S / V$ is the specific pore surface area $\left(\mathrm{cm}^{2} / \mathrm{cm}^{3}\right), \gamma$ is the gyromagnetic ratio of the saturated fluid $(\operatorname{rad} /(\mathrm{s} \cdot \mathrm{T})), G$ is the magnetic field gradient $(\mathrm{Gs} / \mathrm{cm}), \mathrm{D}^{\prime}$ is diffusion coefficient of fluid $\left(\mathrm{cm}^{2} / \mathrm{s}\right)$ and $T_{E}$ is the echo time $(\mathrm{ms})$.

According to NMR principles, $T_{B}$ is much larger than $T_{S}$ and $T_{D}$ when only a single type of fluid resides within the pore. In addition, $1 / T_{B}$ is far smaller than the other two relaxation times, and is therefore negligible. Due to the fact that a uniform magnetic field is employed for an indoor NMR instrument, the corresponding gradient of $G$ is considered to be zero, and $1 / T_{D}$ is negligible. The above formula may therefore be simplified as follows [4]:

$$
\frac{1}{T_{2}}=\frac{1}{T_{S}}=\rho \frac{S}{V}
$$

From Eq. (4), because the value of $\rho$ is unchanged for a kind of medium, it is clear that $T_{S}$ is related to $S / V$, and the relaxation strength increases with increasing $S / V$. The reason for this is mainly because the relaxation rate depends on the frequency with which the proton collides with the surface, i.e., it depends on the ratio of the surface to the volume of the pore $(S / V)$. Therefore, in small pores, the frequency of collisions increases with increasing $S / V$, and the magnitude of $T_{2}$ correspondingly decreases. Otherwise, $T_{2}$ correspondingly increases with increasing pore size. Therefore, the distribution of the $T_{2}$ spectrum can reflect the distribution of pores. The position of the peak is related to the pore size and the area of the peak is related to the number of pores with that corresponding pore size. Figure 7 shows the distribution of the $T_{2}$ spectrum of natural pumice concrete for different values of $N$.

Figure 7 indicates that the distribution of the $T_{2}$ spectrum of the natural pumice concrete presents a total of four peaks. For $N=0-50$, the four peak amplitudes of the $T_{2}$ spectrum all increase, except for the lowest peak value representative of the 


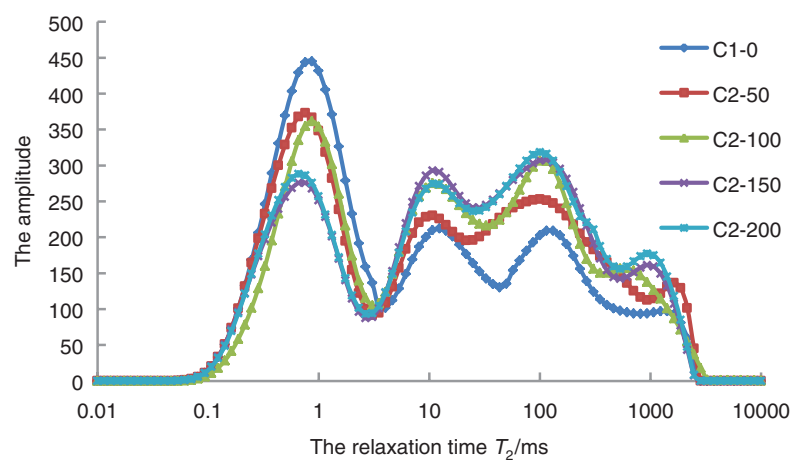

FIGURE 7. The distribution of the $T_{2}$ spectrum of natural pumice concrete for different numbers of freeze-thaw cycles $(\mathrm{N})$.

smallest pores. This indicates that no new fractures are produced in the natural pumice concrete during the initial stage, and the originally small-sized pores are merely enlarged under freeze-thaw cycling. The increased pore size increases the three peak values on the right-hand side. However, at this stage, the extent of pore enlargement and $D$ are both small. For $N=50-100$, the signal strengths of the $T_{2}$ spectrum of the large pores increase. The area of the first peak remains basically unchanged, indicating no increase in the number of small-size pores. The original small-sized pores are enlarged; thus, causing the three peaks on the right-hand side to increase in amplitude.

For $N=100-150$, the amplitude of the lowest peak value of the $T_{2}$ spectrum decreases while the amplitudes of the other three peak values increase slightly. This indicates that, under freeze-thaw action, the generation rate of small pores is small, while the rate at which small pores enlarge is rapid. Therefore, the highest peak of the $T_{2}$ spectrum moves to the right and exhibits a markedly increased amplitude. For $N=150-200$, the peak amplitudes of the $T_{2}$ spectrum all increase, except for that of the second lowest peak, which decreases by a small amount. The amplitude of the lowest peak slightly increases, and the $T_{2}$ spectrum shape moves slightly to the left, namely towards the $T_{2}$ spectrum of smaller pores. This indicates that, under freezethaw action, the natural pumice concrete begins to produce new small pores. With the development of pores from small to large size, the signal strength of the NMR increases, and the value of $D$ for the natural pumice concrete increases.

\subsection{Analysis of the $T_{2}$ spectrum area}

The NMR $T_{2}$ spectrum areas are in direct proportion to the fluid moisture contained inside the natural pumice concrete, and can directly reflect variations in the interior structure of the pores. The total $T_{2}$ spectrum areas can be recorded as the effective porosity of the concrete. Therefore, the $T_{2}$ spectrum area of the concrete after freeze-thaw cycling and the percentage occupied by each peak may directly reflect the variational process of the pores in the concrete. As such, the damage extension process of the natural pumice concrete may be acquired.

Table 7 lists the $T_{2}$ spectrum areas of the natural pumice concrete for various values of $N$. It can be seen that the total $T_{2}$ spectrum area increases with increasing $N$, indicating that the total pore volume of the concrete increases with increasing $N$. It can also be seen that, prior to freeze-thaw cycling, the sum of the first and second peak areas occupies $70.781 \%$ of the total area, indicating that small-sized pores represent the majority of the pores in the concrete. The freeze-thaw damage of the natural pumice concrete is caused mainly by the enlargement of small pores into larger pores, and the development of fractures. The reason for this is that natural pumice concrete is a porous medium material itself, and the pores inside are much more numerous than the coarse aggregate of ordinary concrete. After 0-50 freeze-thaw cycles, the number of concrete pores increases significantly, and the total $T_{2}$ spectrum area increases by $1.38 \%$. The observed increases in the total $T_{2}$ spectrum areas between $50-100$ and 100-150 freeze-thaw cycles are relatively slight, and the respective areas increase by $1.08 \%$ and $0.91 \%$. During this stage, the interior structure of the pumice concrete is affected only slightly by freeze-thaw cycling. However, after 200 freeze-thaw cycles, the total $T_{2}$ spectrum area increases significantly, increasing by $1.51 \%$ relative to the total area at $N=150$, indicating that the freeze-thaw damage of the concrete is rapidly expanded.

TABLE 7. The NMR spectrum areas of the natural pumice concrete after different numbers of freeze-thaw cycles $(N)$

\begin{tabular}{lccccc}
\hline $\begin{array}{l}\text { Number of } \\
\text { cycles } N\end{array}$ & $\begin{array}{c}\text { Total } T_{2} \\
\text { spectrum area }\end{array}$ & $\begin{array}{c}\text { First peak percentage } \\
\text { of the total area (\%) }\end{array}$ & $\begin{array}{c}\text { Second peak percentage } \\
\text { of the total area (\%) }\end{array}$ & $\begin{array}{c}\text { Third peak percentage } \\
\text { of the total area (\%) }\end{array}$ & $\begin{array}{c}\text { Fourth peak percentage } \\
\text { of the total area (\%) }\end{array}$ \\
\hline 0 & 13857 & 53.021 & 17.760 & 23.615 & 4.605 \\
50 & 14048 & 37.275 & 18.544 & 38.631 & 5.550 \\
100 & 14200 & 33.049 & 26.367 & 28.787 & 11.797 \\
150 & 14329 & 28.106 & 26.516 & 36.370 & 9.008 \\
200 & 14545 & 28.660 & 20.605 & 38.736 & 11.999 \\
\hline
\end{tabular}




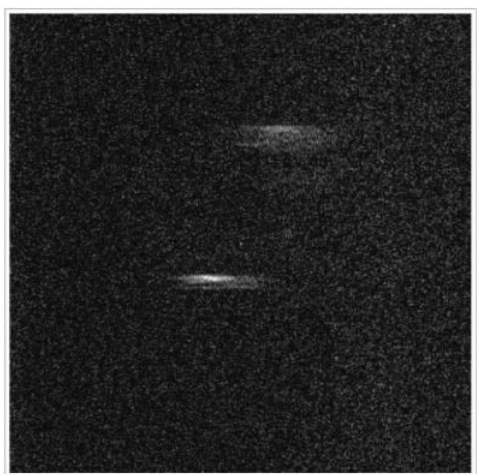

(a) Front image before freeze-thaw cycling

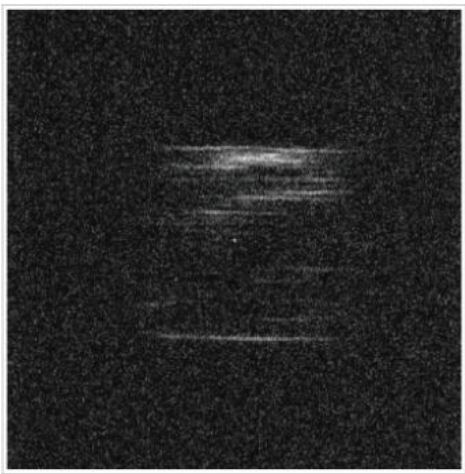

(b) Front image after 100 freeze-thaw cycles

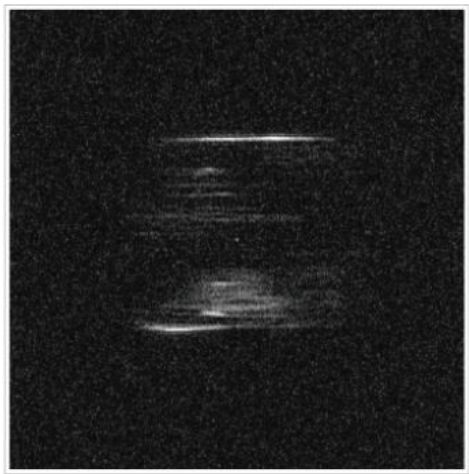

(c) front image after 200 freeze-thaw cycles

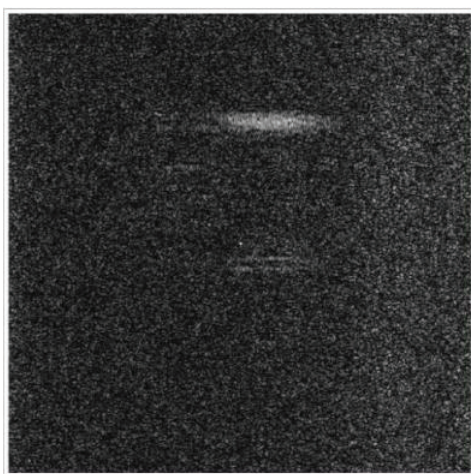

Side image before freeze-thaw cycling

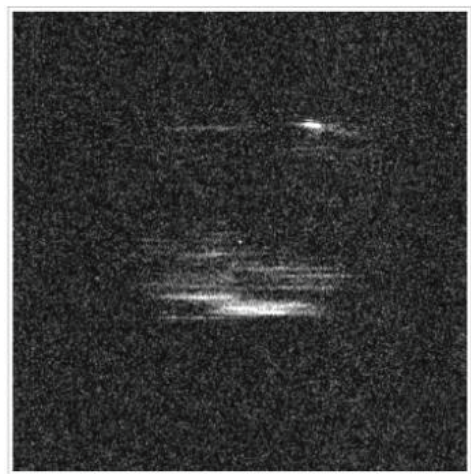

Side image after 100 freeze-thaw cycles

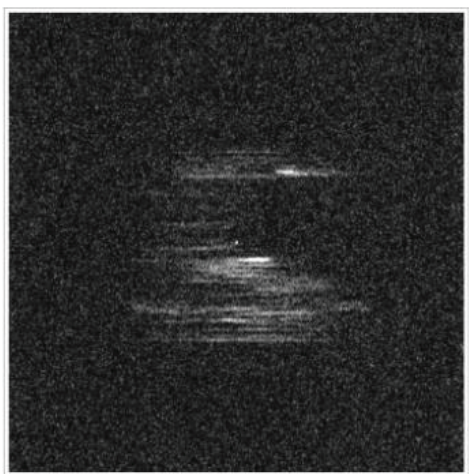

Side image after 200 freeze-thaw cycles

FIGURE 8. The results of magnetic resonance imaging

\section{MRI ANALYSIS}

Magnetic Resonance Imaging (MRI) is a type of biological magnetic spin imaging technology. In accordance with the principles of NMR, we use the different attenuations of the released energy in the interior of substances under different structural environments, and then detect the launched electromagnetic waves through an externally applied magnetic field gradient. In this way, we can determine the location and type of the nucleus of which this substance is composed, and then draw the structural image for the interior of the substance.

The distribution of pore size can be displayed directly through the MRI of natural pumice concrete for different values of $N$. However, due to the fact that the concrete material contains a paramagnetic substance that may interfere with the NMR signals, level-selective imaging is impossible; thus, overall imaging of the concrete was performed. The two-dimensional MRI results of cross-sections of the natural pumice concrete in the two axial 
directions are shown in Figure 8 for different values of $N$. In the image results, the white spots are the semaphores of water molecules, and, therefore, an increasing amount of moisture in the corresponding natural pumice concrete material is indicated by an increasing density of white spots in the image, which also reflects a larger pore size. Otherwise, the pore size is small. The black background color helps to form a sharp contrast for viewing the imaged pores.

Figure 8(a) shows the natural pumice concrete prior to freeze-thaw cycling. The image is largely dark, indicating that the imaged region is mainly comprised of bound fluid with a low water content and a small amount of free fluid. The bright areas of the two images are small, while a small number of bright spots are large. This indicates that several large pores exist in a small area, but small pores occupy the majority of the volume because natural pumice concrete is a porous medium itself.

Figure 8(b) shows the image after 100 freeze-thaw cycles, where the number of bright spots increases slightly. From the front and side images, it can be seen that the large bright spot areas appear inside the test piece, indicating the existence of a large pore structure. Small pore damage extends and develops into large pores and fractures. The size and shape of the pores are clearly displayed.

From Figure 8(c), it can be seen that, after 200 freeze-thaw cycles, the NMR signal increases sharply, and the bright spot area increases significantly. Large pores and fractures appear at the center and surrounding area of the concrete. The damage extends along the horizontal axis direction. The large pores observed in the front and side images are connective.

Through observation of the above images, we can describe the extension process of freeze-thaw damage of the natural pumice concrete. First, the interior small pores of the test piece develop into large pores. The small pores on the external rim of the test piece develop into large pores and fractures. With a continuation of freeze-thaw cycling, the interior small pores of the test piece develop into large pores. Finally, fractures and large pores continue to extend and cause the bright spots to spread nearly throughout the entire section.

\section{CONCLUSIONS}

1. Through ultrasonic testing, it was concluded that, with an increasing number of freeze-thaw cycles $N$, the wave velocity reduction $\eta$ and the degree of damage $D$ both presented rising trends, i.e., an increasing $\eta$ was correlated with an increasing $D$.

2. After $50,100,150$, and 200 freeze-thaw cycles, the total NMR $T_{2}$ spectrum area of the natural pumice concrete changed significantly, with the porosity increasing respectively by $5.2 \%, 7.0 \%$,
$7.5 \%$, and $10.6 \%$. For different values of $N$, the values of the total $T_{2}$ spectrum area vary, while the overall variation presents an increasing trend. This indicates that, with increasing $N$, new pores are generated inside the concrete, and the pore volume occupies an increasing percentage of the total volume. The bound fluid saturation presents a decreasing trend, while the free fluid saturation and permeability present increasing trends.

3. The $T_{2}$ spectrum distribution of the natural pumice concrete mainly presents four peaks. The sum of the areas of the first and second peaks occupies more than $70 \%$ of the total volume prior to freeze-thaw cycling, indicating a large percentage of small-sized pores. With increasing $N$, the area of the first peak decreases gradually, indicating that the small pores of the natural pumice concrete develop into larger pores under freeze-thaw action. However, for $N=200$, the number of small-sized pores increases, indicating a rapid increase in the freeze-thaw damage of the concrete.

4. The results of MRI present the distribution of the interior pores in the freeze-thaw damage extension process of the natural pumice concrete. The MRI results of the natural pumice concrete are largely dark prior to freeze-thaw cycling, and the areas of the bright spots are small, representing a preponderance of small pores. With increasing $N$, the NMR signal increases sharply and the areas of the bright spots enlarge. This directly exhibits the features of damage extension in the interior pores, and provides information for the analysis of the freeze-thaw damage process of the concrete. This is the special advantage of NMR technology.

5. The variation trends of NMR features for natural pumice concrete under freeze-thaw cycling provide reliable testing data for researching the freeze-thaw damage of concrete. In addition, the development and application of NMR technology provide a new non-destructive testing method for the physical testing of concrete, and this will certainly contribute to the development of physical testing technology.

\section{ACKNOWLEDGEMENTS}

This study was supported by the National Natural Science Foundation of China under Grant Nos. 51569021 and 51369023 , by the specialized Research Fund for Doctoral Programs of Higher Education under Grant No. 20121515110002, and by the Natural Science Foundation of Inner Mongolia Autonomous Region under Grant No. 2015MS0564 and 2016BS0503. The work was also partly supported by Program for Innovative Research Team in University under Grant No. IRT13069. 


\section{REFERENCES}

1. Zhi-tao, L. (2002) Prospects of civil engineering construction and prestressing technique in China in the 21 th century. J Southeaet: Nat Sci Ed. 32 [5], 457-459, ISSN:1009-4539.

2. Aitcin, P.C. (2000) Cements of yesterday and today concrete of tomorrow. Cem. Concr. Res. 30 [9], 1349-1359. http://dx.doi.org/10.1016/S0008-8846(00)00365-3.

3. Kok, S.C; Min-Hong, Z. (2002) Water permeability and chloride penetrability of high-strength lightweight aggregate concrete, Cem. Concr. Res. 32 [4], 639-645. http:// dx.doi.org/10.1016/S0008-8846(01)00738-4.

4. Alengaram, U.J.; Abdullah Al Muhit, B.; Zamin bin Jumaat, M. (2013) Utilization of oil palm kernel shell as lightweight aggregate in concrete - A review. Constr. Build. Mater. 38, 161-172. http://dx.doi.org/10.1016/j.conbuildmat. 2012.08.026.

5. Shafigh, P.; Jumaat, M.Z.; Mahmud, H. (2011) Oil palm shell as a lightweight aggregate for production high strength lightweight concrete. Constr. Build. Mater. 25 [4], 1848-1853. http://dx.doi.org/10.1016/j.conbuildmat.2010.11.075.

6. Hong-yun, L. (2009) Experiment Study on Preperties of Air-entrained Natural Pumice Lightweight Aggregate Concrete [D]. Doctoral Dissertation. Inner Mongolia: Inner Mongolia Agricultural University. (in Chinese).

7. Jize, M.; Koichi, A. (2008) Freeze-Thaw Resistance of Lightweight Concrete and Aggregate at Different Freezing Rates. J. Mater. Civil. Eng. 20 [1], 78-84. http://dx.doi. org/10.1061/(ASCE)0899-1561(2008)20:1(78).

8. Hai-long, W.; Xiang-dong, S. (2008) Study of Early Mechanical Properties of Lightweight Aggregate Concrete. B. Chin. Ceram. Soc, 5 [27], 1018-1022, ISSN:1001-1625.

9. Hai-long, W. (2009) The Study on early Mechanics and Frost Resistance of Lightweight Aggregate Concrete [D]. Doctoral Dissertation. Inner Mongolia: Inner Mongolia Agricultural University. (in Chinese).

10. Duzgun, O.A.; Gul, R.; Aydin, A.C. (2005) Effect of steel fibers on the mechanical properties of natural lightweight aggregate concrete. Mater. Lett. 59 [27], 3357-3363. http:// dx.doi.org/10.1016/j.matlet.2005.05.071.

11. Yasar, E.; Atis, C.D.; Kilic, A.; Gulsen, H. (2003) Strength properties of lightweight concrete made with basaltic pumice and fly ash. Mater. Lett. 57 [15], 2267-2270. http:// dx.doi.org/10.1016/S0167-577X(03)00146-0 http://www. sciencedirect.com/science/article/pii/S0167577X03001460.

12. Tanyildizi, H. (2008) Effect of temperature, carbon fibers, and silica fume on the mechanical properties of lightweight concretes. New. Carbon. Mater. 23 [4], 339-344. http:// dx.doi.org/10.1016/s1872-5805(09)60005-6.

13. Alshihri, M.M.; Azmy, A.M.; El-Bisy, M.S. (2009) Neural networks for predicting compressive strength of structural light weight concrete. Constr. Build. Mater. 23 [6], 2214-2219. http://dx.doi.org/10.1016/j.conbuildmat.2008.12.003.

14. Sengul, O.; Azizi, S.; Karaosmanoglu, F.; Tasdemir, M.A. (2011) Effect of expanded perlite on the mechanical properties and thermal conductivity of lightweight concrete. Energ Buildings. 43 [2-3], 671-676. http://dx.doi.org/10.1016/j. enbuild.2010.11.008.

15. Wei-xuan, Z. (2006) Analytical study of temperature field and temperature stress of concrete structure under freezing and thawing environment [D]. Master. Dissertation, Harbin institute of technology. (in Chinese).

16. Xiao-xiao, W. (2012) Study on physical properties of lightweight aggregate concrete affected by mineral admixture [D]. Master Dissertation. Inner Mongolia: Inner Mongolia Agricultural University. (in Chinese).

17. Khokhrin, N.K. Durability of Lightweight Concrete Structure Members, (Kuibyshov, U.S.S.R.).

18. Hassanpour, M. (2012) Lightweight aggregate concrete fiber reinforcement-A review. Constr. Build. Mater. 37, 452-461. http://dx.doi.org/10.1016/j.conbuildmat.2012.07.071.

19. Hai-long, W.; Xiang-dong, S.; Xiao-xiao, W. (2013) Study of Carbon Fiber Improved Pumice Concrete Mechanical Properities. J. Build. Mater. 16 [2], 232-236, ISSN:1007-9629.
20. Kockal, N.U.; Ozturan, T. (2010) Effects of lightweight fly ash aggregate properties on the of lightweight concretes. J. Hazard. Mater. 179 [1-3], 954-965. http://dx.doi.org/ 10.1016/j.jhazmat.2010.03.098.

21. Kockal, N.U.; Ozturan, T. (2011) Durability of lightweight concretes with lightweight fly ash aggregates. Constr. Build. Mater. 25 [3], 1430-1438. http://dx.doi.org/10.1016/j. conbuildmat.2010.09.022.

22. Hossain, K.M.A.; Ahmed, S.; Lachemi, M. (2011) Lightweight concrete incorporating pumice based blended cement and aggregate: Mechanical and durability characteristics. Constr. Build. Mater. 25 [3], 1186-1195. http:// dx.doi.org/10.1016/j.conbuildmat.2010.09.036.

23. Hong-zhi, C. (2007) Mechanical properties of lightweight aggregate concrete--effect of lightweight aggregate on the concrete [D]. Ph.D. City University of Hong Kong. (in Chinese)

24. Amor, B.F.; Mohamed, K.; Pierre, M. (2010) Valorization of coarse rigid polyurethane foam waste in lightweight aggregate concrete. Constr. Build. Mater. 24, 1069-1077. http:// www.sciencedirect.com/science/article/pii/S0950061809 00395X.

25. Masad, E.; Omari, A.; Chen, H.C. (2007) Computations of permeability tensor coefficients and anisotropy of asphalt concrete based on microstructure simulation of fluid flow. Comp. Mater. Sci. 40 [4], 449-459. http://dx.doi. org/10.1016/j.commatsci.2007.01.015.

26. Lu, S.; Landis, E.; Keane, D. (2006) X-ray microtomographic studies of pore structure and permeability in Portland cement concrete. Mater. Struct. 39 [6], 11-20. http://link. springer.com/article/10.1617/s11527-006-9099-7.

27. Chung, S.Y.; Han, T.S. (2013) Correlation between loworder probability distribution functions and percolation of porous concrete. Mag. Conc. Res. 65 [7], 448-460. http:// dx.doi.org/10.1680/macr.12.00125.

28. Gallucci, E.; Scribener, K.; Groso, A.; Stampanoni, M.; Margaritondo, G. (2007) 3D experimental investigation of the microstructure of cement pastes using synchrotron X-ray microtomography ( $\mu \mathrm{CT})$. Cem. Conc. Res. 37 [3], 360-368. http://dx.doi.org/10.1016/j.cemconres.2006.10.012.

29. Chotard, T.; Boncoeur-Martel, M.; Smith, A.; Dupuy, J.; Gault, C. (2003) Application of X-ray compute tomography to characterise the early hydration of calcium aluminate cement. Cem. Concr. Compos. 25 [1], 145-152. http:// dx.doi.org/10.1016/S0958-9465(01)00063-4.

30. Sang-Yeop, C.; Tong-Seok, H.; Tae, S.Y.; Kwang, S.Y. (2013) Evaluation of the anisotropy of the void distribution and the stiffness of lightweight aggregates using CT imaging, Constr. Build. Mater. 48, 998-1008. http://dx.doi. org/10.1016/j.conbuildmat.2013.07.082.

31. Chao-mo, Z.; Zhen-biao, C.; Zhan-song, Z. et al. (2009) Characteristics of reservoir rock pore fractal structure based on nuclear magnetic resonance (NMR) $T_{2}$ distribution. Journal of Oil and Gas Technology. 29 [4], 80-86, ISSN:1000-9752.

32. Sheng, W. (2009) Analysis of rock pore structural characteristic by nuclear magnetic resonance. Xinjiang Petroleum Geology. 30 [6]. 768-770, ISSN:1001-3873.

33. Jie-lin, L; Ke-ping, Z; Ya-min, Z; Yu-juan, X. (2012) Experimental Study of Rock porous Structure Damage Characteristics Under Condition of freezing-thawing Cycles Based on Nuclear Magnetic Resonance Technique [J]. Chin. J. Rock. Mech. Eng. 31 [6], 1208-1214, ISSN:1000-6915.

34. Qing-xin, Z.; Pei-pei, K. (2013) Influence of Mechanical Damage on Frost Resistance of Concrete. J. Build. Mater. 16 [2], 326-334, ISSN:1007-9629.

35. Coates, G.; Zhi-xiao, L.; Prammer, M. (2007) NMR logging principles and application [M]. Translated by MENG Fanying. Beijing: Petroleum Industry Press. 36-39, ISBN: 9787502161958

36. Jun-chang, S. (2010) Experimental study of Micro-structure and NMR Features of Volcanic Gas Reservior [D]. Master Dissertation. Graduate University of Chinese Academy of Sciences. (in Chinese). 